\title{
Half-dose and half-fluence photodynamic therapy for central serous chorioretinopathy
}

\author{
Julie M. Rosenthal ${ }^{1 \dagger}$ and Christina J. Flaxe ${ }^{2^{*}}$ \\ *Correspondence: flaxelc@ohsu.edu

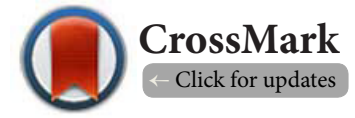 \\ 'These authors contributed equally to this work. \\ ${ }^{1}$ Retinal and Ophthalmic Consultants, Northfield, New Jersey, USA. \\ ${ }^{2}$ Casey Eye Institute, Oregon Health and Science University, Portland, Oregon, USA.
}

\begin{abstract}
Background: Chronic central serous chorioretinopathy presents a treatment challenge. Photodynamic therapy has been used successfully but with side effects; thus, the authors explored half-dose and half-fluence photodynamic therapy as lower-risk alternatives.
\end{abstract}

Methods: Retrospective medical record review of patients with chronic or recurrent central serous chorioretinopathy who received half-dose or half-fluence photodynamic therapy from May 2008 through March 2011 at a tertiary care referral center in Portland, Oregon, USA. The authors recorded demographics, visual acuity, and change in central retinal thickness as measured by optical coherence tomography.

Results: Eight patients aged 46 to 80 years (11 eyes) were treated for central serous chorioretinopathy with half-dose or half-fluence photodynamic therapy, or with both of these treatment modalities on different occasions. Visual acuity before treatment ranged from 20/15 to 20/100; after treatment, visual acuity also ranged from 20/15 to 20/100. The authors noted no significant differences between half-dose and half-fluence photodynamic therapy and no serious treatment complications.

Conclusions: Half-dose and half fluence photodynamic therapy are safe and effective treatment alternatives for chronic central serous chorioretinopathy.

Keywords: Central serous chorioretinopathy, photochemotherapy, retina, retinal detachment, retinal pigment epithelium

\section{Introduction}

Central serous chorioretinopathy (CSCR) is characterized by a serous retinal detachment of the neurosensory retina with 1 or more areas of leakage from the level of the retinal pigment epithelium (RPE) [1]. The major symptoms include visual disturbances from decreased vision, metamorphopsia, and micropsia to central scotomas. CSCR is most common in young adults, occurs more frequently in males, and usually causes symptoms unilaterally, although evidence of disease with RPE changes is often noted bilaterally. While most patients with the classic form of CSCR have an acute episode of decreased vision and recover fully, a small number of patients develop the chronic or recurrent form of the disease. These patients have diffuse RPE changes and chronic or recurrent subretinal fluid (SRF). Patients with chronic CSCR tend to be older than those who have a single acute episode; CSCR may be associated with the use of corticosteroid medications in oral, topical, intranasal, injected, or any other form. Vision loss can occur in patients who have chronic or recurrent fluid leakage and persistent serous retinal detachment.

Treatment of chronic CSCR is a frustrating challenge for patients and retinal specialists. Many treatment modalities have been investigated, including rifampin [2], finasteride [3], transpupillary thermotherapy [4], ketoconazole [5], mifepristone [6], indocyanine green-mediated laser treatment $[7,8]$, propranolol [9], focal laser [9], intravitreal bevacizumab [10-13], and more recently eplerenone [14], all with limited success. With a list this long, chronic CSCR clearly defies easy treatment.

There has been considerable interest in photodynamic therapy (PDT) as a treatment for chronic CSCR, and it has been used successfully in some patients [15]. Indocyanine green angiography (ICGA) has shown that CSCR primarily affects the choroidal circulation, with resulting areas of choroidal hyperpermeability [16]. PDT with verteporfin is presumed to treat CSCR by closing or narrowing vascular channels in the choriocapillaris, leading to hypoperfusion and reduced exudation with subsequent long-term choroidal vascular remodeling [17]. However, treatment success is limited by complications, including RPE atrophy and tears, choroidal neovascularization, and ischemia [18]. In an effort to minimize complications, PDT has been used at half the regular dose, fluence, or both [19-23]. This has been shown to reduce SRF 
and improve visual acuity (VA) and retinal sensitivity. We aimed to determine whether half-dose or half-fluence PDT, or both, were safe and effective in our practice at a tertiary care referral center in Portland, Oregon, USA. We achieved this aim in our study and here report our experience with these treatments for chronic or recurrent CSCR.

\section{Methods}

We performed a retrospective medical record review of patients treated with PDT for chronic or recurrent CSCR at Casey Eye Institute, Oregon Health \& Science University (OHSU), from May 2008 through March 2011. We certify that all applicable institutional and governmental regulations concerning the ethical use of human volunteers were followed during this research. Informed consent for the treatment was obtained from all patients, and the OHSU Institutional Review Board approved the study.

All patients received half-dose or half-fluence PDT. We excluded patients for whom at least 8 weeks of follow-up information was not available. Patients who were included had chronic CSCR diagnosed by fluorescein angiography and confirmed by OCT, ICGA, or both. Diagnostic criteria for CSCR included the presence of SRF for $>6$ months, RPE changes induced by chronic or recurrent fluid with fluid present at the time of treatment, or both. Patients were excluded if they had vision-threatening conditions not related to CSCR, fluorescein hypersensitivity, or any contraindications for PDT.

We studied 11 eyes of 8 patients ( 7 men and 1 woman), aged from 46 to 80 years. All patients received half-dose or half-fluence PDT or both to treat chronic or recurrent CSCR. Half-dose PDT consisted of $3 \mathrm{mg} / \mathrm{m}^{2}$ verteporfin (Visudyne; Valeant Pharmaceuticals North America, LLC, Bridgewater, New Jersey, USA) instead of the standard dose of $6 \mathrm{mg} / \mathrm{m}^{2}$. Half-fluence PDT consisted of laser at a fluence of $25 \mathrm{~J} / \mathrm{cm}^{2}$ instead of the standard $50 \mathrm{~J} / \mathrm{cm}^{2}$. Six patients (8 eyes) received half-dose PDT, 1 eye of 1 patient received half-fluence PDT and 2 eyes of 1 patient were treated with both half-dose and half-fluence PDT.

All patients received verteporfin by intravenous line over 10 minutes. Five minutes after the infusion was stopped, patients were treated with 83 seconds of PDT ( $689 \mathrm{~nm}$ diode; Lumenis Opal Photoactivator; Lumenis, Inc., Santa Clara, California, USA). A registered nurse performed all injections, and 1 of 2 retinal specialists performed the laser treatment based on pretreatment fluorescein angiography or ICGA showing leakage points of choroidal hyperpermeability. We recorded patient demographic information, VA data, number of treatments, and change in central macular thickness (CMT) as measured by OCT.

\section{Results}

Patients were followed from 3 to 30 months after treatment. The mean follow-up time was 18.5 months (range 4-41 months) of observation, including observation before treatment and
8 months (range 3-18 months) of follow-up after PDT was initiated. Results for VA and CMT are shown in the Tables 1 and $\mathbf{2}$. Examples of patient outcomes are given in (Figures 1 and 2). No patient experienced a serious complication, such as choroidal neovascularization or vision loss. Treatment was generally well tolerated.

\section{Discussion}

Table 1. Results of half-dose and half-fluence photodynamic therapy for central serous chorioretinopathy*.

\begin{tabular}{ll}
\hline Parameter & Result \\
\hline Initial VA $^{\dagger}$ & $20 / 15-20 / 100$ \\
Final VA & $20 / 15-20 / 100$ \\
VA change & -1 to +2 lines \\
Mean initial CMT ${ }^{\ddagger}$ thickness & $275 \mu \mathrm{m}$ \\
Mean CMT change after 1 treatment & $-53 \mu \mathrm{m}$ \\
Mean final CMT change & $-35 \mu \mathrm{m}$ \\
Mean number of treatments & 2.2 (range 1-6, mode 1) \\
\hline
\end{tabular}

*The study included 11 eyes of 8 patients.

Abbreviations: $(\dagger) \mathrm{VA}$, visual acuity;

(‡) CMT, central macular thickness.

Table 2. Patients treated with half-dose and half-fluence photodynamic therapy for central serous chorioretinopathy (8 Patients, 11 Eyes).

\begin{tabular}{llllll}
\hline Patient & $\begin{array}{l}\text { Age at } \\
\text { Presentation }\end{array}$ & Sex & $\begin{array}{l}\text { Visual acuity at } \\
\text { first treatment }\end{array}$ & $\begin{array}{l}\text { Eye(s) } \\
\text { studied }\end{array}$ & Treatment \\
\hline 1 & 45 & M & $20 / 20$ & OD & $\mathrm{D}^{*}$ \\
2 & 57 & M & $\begin{array}{l}20 / 100 \mathrm{OD}^{\ddagger}, \\
20 / 20 \mathrm{OS}^{5}\end{array}$ & OUll & $\mathrm{F}^{\dagger}$ and D \\
& & & & \\
3 & 56 & $\mathrm{M}$ & $20 / 40$ & $\mathrm{OD}$ & $\mathrm{D}$ \\
4 & 45 & $\mathrm{M}$ & $20 / 50$ & $\mathrm{OD}$ & $\mathrm{D}$ \\
5 & 57 & $\mathrm{M}$ & $20 / 80 \mathrm{OD}$, & $\mathrm{OU}$ & $\mathrm{D}$ \\
& & & $20 / 20 \mathrm{OS}$ & & \\
6 & 80 & $\mathrm{M}$ & $20 / 100$ & $\mathrm{OD}$ & $\mathrm{D}$ \\
7 & 57 & $\mathrm{M}$ & $20 / 125$ & $\mathrm{OS}$ & $\mathrm{F}$ \\
8 & 46 & $\mathrm{~F}$ & $20 / 30$ OD, & OU & $\mathrm{D}$ \\
& & & $20 / 30$ OS & & \\
\hline
\end{tabular}

Abbreviations: $\left(^{*}\right) \mathrm{D}$, half-dose photodynamic therapy; $(\dagger) \mathrm{F}$, half-fluence photodynamic therapy; ( $\$)$ OD, right eye; (\$) OS, left eye; (\|) OU, both eyes.

We found half-dose and half-fluence PDT to be safe and effective treatment alternatives for patients with chronic or recurrent CSCR. These treatments were well tolerated with minimal side effects and without incidence of choroidal hypoperfusion or catastrophic vision loss. However, some patients required repeated treatments to achieve or maintain improvement.

There is currently no standard treatment for either acute or chronic CSCR, though various attempts have been made at treating the disease, beginning with standard laser to seal off potential leakage points in the acute form [24-26]. However, although laser treatment may shorten the duration 

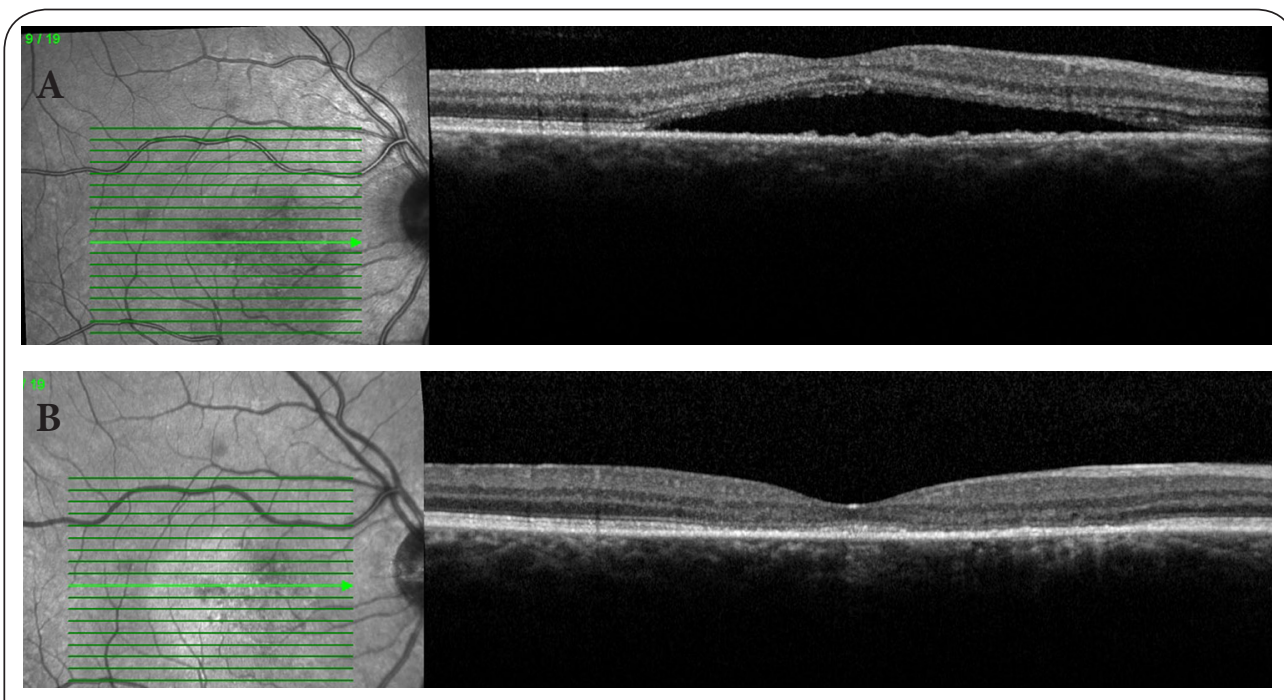

Figure 1. Central Serous Chorioretinopathy Before and After Half-Dose Photodynamic Therapy.

Spectral domain optical coherence tomography of right eye of 45-year-old man with central serous chorioretinopathy. Grids in (A) and (B) show the sampling area. Arrows show the direction of sampling (left to right) and orientation of the slice relative to the right photo.

(A) Subretinal fluid before half-dose PDT.

(B) Three months after treatment, fluid has resolved and CMT decreased from $399 \mu \mathrm{m}$ to 197 $\mu \mathrm{m}$. This figure also shows loss of outer retinal structures centrally with resolution of SRF.

of the disease, it has not been found to affect the final VA or recurrence rate of CSCR. Smretschnig et al., utilized half-fluence PDT to treat acute CSCR and reported excellent outcomes in $\mathrm{VA}$ and a significant reduction in central foveal thickness on $\mathrm{OCT}$, with a recurrence rate of 0 at 1 year without significant complications [27]. Their study differs from ours in that they were treating acute CSCR with symptom duration of 12 weeks or less, whereas our patients had symptoms and presence of SRF for longer than 6 months. However, in a finding similar to ours, their patients had no significant adverse events following treatment. In a later study, the same group utilized the same half-fluence PDT protocol for patients with chronic CSCR who had symptoms for 6 months or longer [28]. They reported resolution of SRF in $100 \%$ of eyes at 1 month and constant VA gain up to month 12 with minimal side effects. These results are similar to ours. However, these investigators utilized halffluence PDT for all patients, while most of ours underwent the half-dose treatment. Several studies have evaluated the use of half-dose PDT $\left(3 \mathrm{mg} / \mathrm{m}^{2}\right)$ to treat chronic CSCR. The largest of these, by Chan et al., [29], included 48 eyes with 1 year of follow-up and demonstrated the resolution of SRF in $95 \%$ of eyes and improvement in VA compared to a control group. This is a much larger study than ours with similar results.

More recently, groups have attempted to compare reducedfluence or reduced dose PDT, or both, with conventional PDT. Reibaldi et al., [21] evaluated low-fluence PDT $\left(25 \mathrm{~J} / \mathrm{cm}^{2}\right)$ versus standard fluence $\left(50 \mathrm{~J} / \mathrm{cm}^{2}\right)$ and found improvement in bestcorrected VA at 12 months in both groups with resorption of $\mathrm{SRF}$ in a significant number of eyes. However, these authors also noted significant choriocapillaris nonperfusion in $44 \%$ of eyes treated with standard-fluence PDT versus $0 \%$ in those treated with reduced-fluence PDT. Shin et al., reported similar findings [30]. Silva et al., published a 4-year follow-up study of conventional PDT for chronic CSCR and reported no systemic or ocular side effects in 46 eyes of 42 patients and long-term improvement both anatomically and visually. Further, only $8.6 \%$ of eyes required more than 1 treatment over the 4 -year follow-up period [31]. We did not have enough eyes in our half-fluence group to offer any comparison with the halfdose group.

\section{Conclusion}

Our study is limited by the small number of patients and potentially by the use of central macular thickness as an outcome measure. Measurement of central macular thickness may not reflect the full extent of SRF, and this method misses non-central fluid. Other potential limitations are the retrospective nature of our study and the absence of a control group. While treatment does not necessarily improve Snellen VA measurements, our patients experienced an improved quality of vision and improvement in CMT. This has been quantified in other studies by retinal sensitivity measurements [32]. Our work adds to the body of knowledge on half-dose and half-fluence photodynamic therapy as treatment options for this challenging clinical problem by showing that either treatment, or both together, can be helpful. Further, our work helps lay the groundwork for future studies using qualitative measurements of visual acuity to determine the effectiveness 


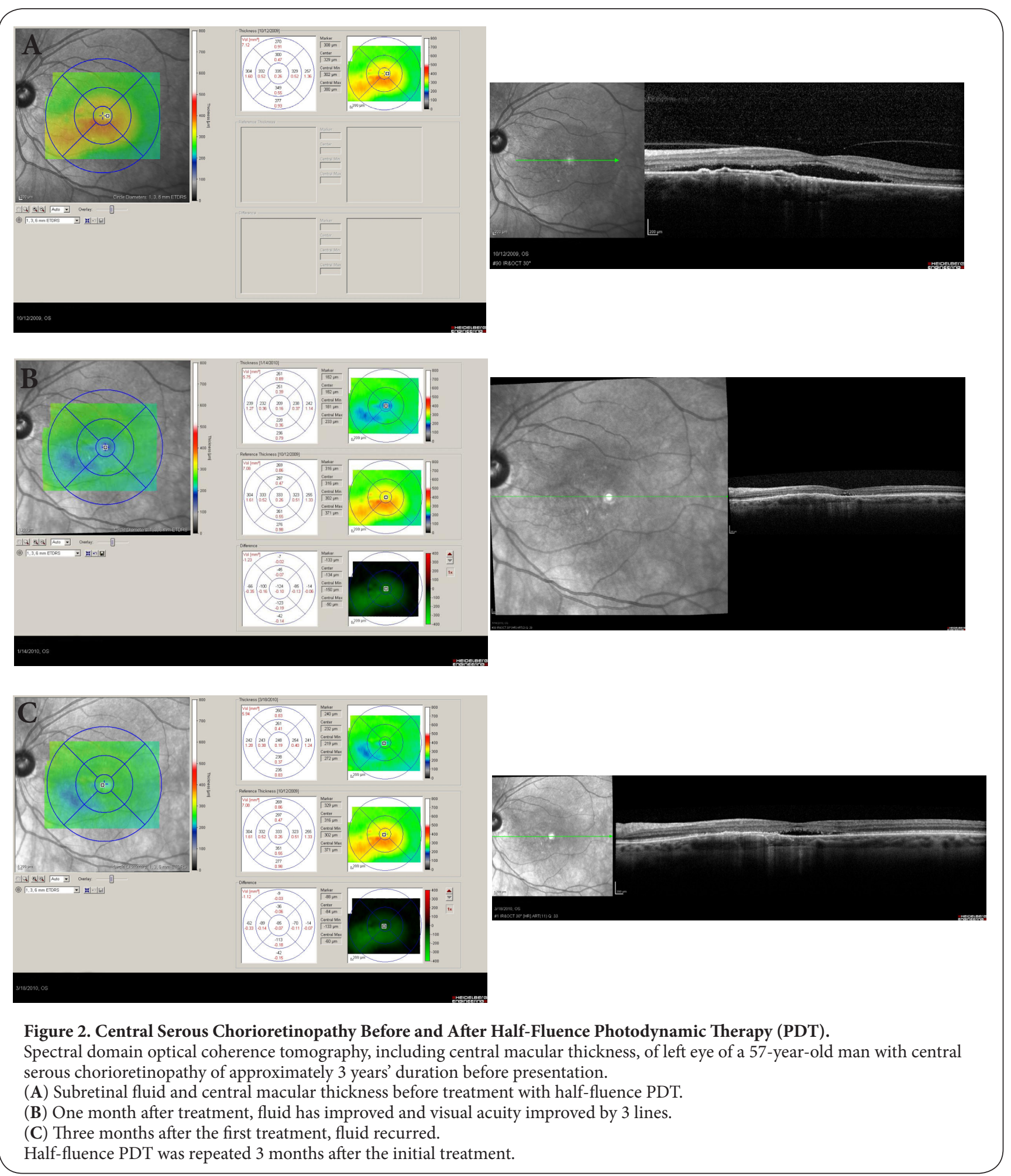


Rosenthal et al. Journal of Eye and Ophthalmology 2014,

of these treatments further compared to conventional PDT.

\section{Competing interests}

The authors declare that they have no competing interests.

Authors' contributions

\begin{tabular}{|l|c|c|}
\hline Authors' contributions & JMR & CJF \\
\hline Research concept and design & -- & $\checkmark$ \\
\hline Collection and/or assembly of data & $\checkmark$ & $\checkmark$ \\
\hline Data analysis and interpretation & $\checkmark$ & $\checkmark$ \\
\hline Writing the article & $\checkmark$ & $\checkmark$ \\
\hline Critical revision of the article & $\checkmark$ & $\checkmark$ \\
\hline Final approval of article & $\checkmark$ & $\checkmark$ \\
\hline Statistical analysis & $\checkmark$ & $\checkmark$ \\
\hline
\end{tabular}

Acknowledgement

This work was supported in part by Research to Prevent Blindness, New York, NY, with an unrestricted grant to Casey Eye Institute, Oregon Health \& Science University. Assistance with figures was provided by George Petricek, medical photographer, Casey Eye Institute, Portland, OR, USA. Medical editing assistance was provided by Genevieve J. Long, Portland, OR, USA.

Publication history

Editor: Venkata R. M. Chavali, University of Pennsylvania, USA. Received: 31-Jan-2014 Final Revised: 30-Apr-2014

Accepted: 09-May-2014 Published: 20-May-2014

\section{References}

1. Gass JD. Pathogenesis of disciform detachment of the neuroepithelium. Am J Ophthalmol. 1967; 63:Suppl:1-139. | PubMed

2. Steinle NC, Gupta N, Yuan A and Singh RP. Oral rifampin utilisation for the treatment of chronic multifocal central serous retinopathy. $\mathrm{BrJ}$ Ophthalmol. 2012; 96:10-3. | Article | PubMed

3. Forooghian F, Meleth AD, Cukras C, Chew EY, Wong WT and Meyerle CB. Finasteride for chronic central serous chorioretinopathy. Retina. 2011; 31:766-71. | Article | PubMed Abstract | PubMed Full Text

4. Hussain N, Khanna R, Hussain A and Das T. Transpupillary thermotherapy for chronic central serous chorioretinopathy. Graefes Arch Clin Exp Ophthalmol. 2006; 244:1045-51. | Article | PubMed

5. Meyerle CB, Freund KB, Bhatnagar $P$, Shah $V$ and Yannuzzi LA. Ketoconazole in the treatment of chronic idiopathic central serous chorioretinopathy. Retina. 2007; 27:943-6. | Article | PubMed

6. Nielsen JS and Jampol LM. Oral mifepristone for chronic central serous chorioretinopathy. Retina. 2011; 31:1928-36. | Article | PubMed

7. Penha FM, Aggio FB and Bonomo PP. Severe retinal thermal injury after indocyanine green-mediated photothrombosis for central serous chorioretinopathy. Am J Ophthalmol. 2007; 143:887-9. | Article | PubMed

8. Ricci F, Missiroli F, Regine F, Grossi M and Dorin G. Indocyanine green enhanced subthreshold diode-laser micropulse photocoagulation treatment of chronic central serous chorioretinopathy. Graefes Arch Clin Exp Ophthalmol. 2009; 247:597-607. | Article | PubMed

9. Tatham $A$ and Macfarlane $A$. The use of propranolol to treat central serous chorioretinopathy: an evaluation by serial OCT. J Ocul Pharmacol Ther. 2006; 22:145-9. | Article | PubMed

10. Schaal KB, Hoeh AE, Scheuerle A, Schuett $F$ and Dithmar S. Intravitreal bevacizumab for treatment of chronic central serous chorioretinopathy. Eur J Ophthalmol. 2009; 19:613-7. | Article | PubMed

11. Lim SJ, Roh MI and Kwon OW. Intravitreal bevacizumab injection for central serous chorioretinopathy. Retina. 2010; 30:100-6. | Article | PubMed
12. Lim JW and Kim MU. The efficacy of intravitreal bevacizumab for idiopathic central serous chorioretinopathy. Graefes Arch Clin Exp Ophthalmol. 2011; 249:969-74. | Article | PubMed

13. Wong IY, Koo SC and Chan CW. Intravitreal bevacizumab injection for central serous chorioretinopathy. Retina. 2011; 31:198-9; author reply 199. | Article | PubMed

14. Zhao M, Celerier I, Bousquet E, Jeanny JC, Jonet L, Savoldelli M, Offret $\mathrm{O}$, Curan A, Farman N, Jaisser F and Behar-Cohen F. Mineralocorticoid receptor is involved in rat and human ocular chorioretinopathy. J Clin Invest. 2012; 122:2672-9. | Article | PubMed Abstract | PubMed Full Text

15. Ruiz-Moreno JM, Lugo FL, Armada F, Silva R, Montero JA, Arevalo JF, Arias $L$ and Gomez-Ulla F. Photodynamic therapy for chronic central serous chorioretinopathy. Acta Ophthalmol. 2010; 88:371-6. | Article | PubMed

16. Piccolino FC and Borgia L. Central serous chorioretinopathy and indocyanine green angiography. Retina. 1994; 14:231-42. | Article | PubMed

17. Chan WM, Lam DS, Lai TY, Tam BS, Liu DT and Chan CK. Choroidal vascular remodelling in central serous chorioretinopathy after indocyanine green guided photodynamic therapy with verteporfin: a novel treatment at the primary disease level. Br J Ophthalmol. 2003; 87:1453-8. | Article | PubMed Abstract | PubMed Full Text

18. Lee PY, Kim KS and Lee WK. Severe choroidal ischemia following photodynamic therapy for pigment epithelial detachment and chronic central serous chorioretinopathy. Jpn J Ophthalmol. 2009; 53:52-6. I Article | PubMed

19. Lim JW, Kang SW, Kim YT, Chung SE and Lee SW. Comparative study of patients with central serous chorioretinopathy undergoing focal laser photocoagulation or photodynamic therapy. Br J Ophthalmol. 2011; 95:514-7. | Article | PubMed

20. Nicolo M, Zoli D, Musolino M and Traverso CE. Association between the efficacy of half-dose photodynamic therapy with indocyanine green angiography and optical coherence tomography findings in the treatment of central serous chorioretinopathy. Am J Ophthalmol. 2012; 153:474-480 e1. | Article | PubMed

21. Reibaldi M, Boscia F, Avitabile T, Uva MG, Russo A, Zagari M, Occhipinti F, Russo V, Reibaldi A and Longo A. Functional retinal changes measured by microperimetry in standard-fluence vs low-fluence photodynamic therapy in chronic central serous chorioretinopathy. Am J Ophthalmol. 2011; 151:953-960 e2. | Article | PubMed

22. Rouvas A, Stavrakas P, Theodossiadis PG, Stamatiou P, Milia M, Giannakaki $E$ and Datseris I. Long-term results of half-fluence photodynamic therapy for chronic central serous chorioretinopathy. Eur J Ophthalmol. 2012; 22:417-22. | Article | PubMed

23. Shinojima A, Kawamura A, Mori R, Fujita K and Yuzawa M. Detection of morphologic alterations by spectral-domain optical coherence tomography before and after half-dose verteporfin photodynamic therapy in chronic central serous chorioretinopathy. Retina. 2011; 31:1912-20. | Article | PubMed

24. Burumcek E, Mudun A, Karacorlu S and Arslan MO. Laser photocoagulation for persistent central serous retinopathy: results of long-term follow-up. Ophthalmology. 1997; 104:616-22. | Article | PubMed

25. Robertson DM. Argon laser photocoagulation treatment in central serous chorioretinopathy. Ophthalmology. 1986; 93:972-4. | Article | PubMed

26. Robertson DM and Ilstrup D. Direct, indirect, and sham laser photocoagulation in the management of central serous chorioretinopathy. Am J Ophthalmol. 1983; 95:457-66. | PubMed

27. Smretschnig E, Ansari-Shahrezaei S, Moussa S, Glittenberg C, Krebs I and Binder S. Half-fluence photodynamic therapy in acute central serous chorioretinopathy. Retina. 2012; 32:2014-9. | Article | PubMed

28. Smretschnig E, Ansari-Shahrezaei S, Hagen S, Glittenberg C, Krebs I and Binder $S$. Half-fluence photodynamic therapy in chronic central serous chorioretinopathy. Retina. 2013; 33:316-23. | Article | PubMed

29. Chan WM, Lai TY, Lai RY, Tang EW, Liu DT and Lam DS. Safety enhanced photodynamic therapy for chronic central serous chorioretinopathy: one-year results of a prospective study. Retina. 2008; 28:85-93. | Article 
Rosenthal et al. Journal of Eye and Ophthalmology 2014,

http://www.hoajonline.com/journals/pdf/2055-2408-1-2.pdf

I PubMed

30. Shin JY, Woo SJ, Yu HG and Park KH. Comparison of efficacy and safety between half-fluence and full-fluence photodynamic therapy for chronic central serous chorioretinopathy. Retina. 2011; 31:119-26. | Article | PubMed

31. Silva RM, Ruiz-Moreno JM, Gomez-Ulla F, Montero JA, Gregorio T, Cachulo ML, Pires IA, Cunha-Vaz JG and Murta JN. Photodynamic therapy for chronic central serous chorioretinopathy: a 4-year follow-up study. Retina. 2013; 33:309-15. | Article | PubMed

32. Senturk F, Karacorlu M, Ozdemir H, Karacorlu SA and Uysal O. Microperimetric changes after photodynamic therapy for central serous chorioretinopathy. Am J Ophthalmol. 2011; 151:303-9 e1. | Article | $\underline{\text { PubMed }}$

\section{Citation:}

Rosenthal JM and Flaxel CJ. Half-dose and halffluence photodynamic therapy for central serous chorioretinopathy. J Eye Ophthalmol. 2014; 1:2. http://dx.doi.org/10.7243/2055-2408-1-2 